\title{
Otimização e correlação sensorial de formulações de doces em pasta de Araticum (Annona crassiflora Mart.)
}

\author{
Sensory optimization and correlation of paste Araticum (Annona crassiflora Mart.) preserves
} formulations

\author{
M. O. S. Oliveira ${ }^{1 *}$; R. A. Morais ${ }^{1}$; B. B. Dias ${ }^{1}$; C. M. S. Soares ${ }^{1}$; J. F. M. Silva ${ }^{2}$; \\ G. A. S. Martins ${ }^{1}$ \\ ${ }^{1}$ Laboratório de Cinética e Modelagem de Processos, Universidade Federal do Tocantins, 77001090, Palmas- \\ Tocantins, Brasil \\ ${ }^{2}$ Laboratório de Microbiologia Geral e Aplicada, Universidade Federal do Tocantins, 77001090, Palmas- \\ Tocantins, Brasil \\ *mariaoliviaeng @ gmail.com
(Trabalho avaliado e selecionado pela Comissão do III CTOCTA)
}

\begin{abstract}
Araticum é um fruto nativo do bioma Cerrado que possui alto potencial nutricional, funcional e econômico. No entanto, o fruto é sazonal, o seu processamento além de agregar valor, permite o aumento da vida útil e o consumo de produtos independente do período de colheita. Diante disso, o presente trabalho tem por objetivo aproveitar o fruto do Araticum sob a forma de doce em pasta com substituição da pectina comercial por albedo de maracujá, bem como a avaliação da qualidade microbiológica e nutricional, e otimização sensorial das formulações, com foco na inserção do fruto no mercado consumidor. Para o processamento, foi utilizado um delineamento experimental $2^{3}$ com 11 ensaios e 3 variáveis independentes (ácido cítrico, polpa/açúcar e albedo de maracujá). Foram realizadas análises microbiológicas, testes sensoriais de aceitação para otimização das formulações, correlação entre os atributos sensoriais. As 11 formulações obtiveram boa aceitação dos provadores, sendo que, as formulações 9, 10 e 11 foram preferidas pelos modelos de otimização.

Palavras-chave: Araticum, qualidade sensorial, superfície de resposta.
\end{abstract}

Araticum is a native fruit of the Cerrado biome that has high nutritional, functional and economic potential. However, the fruit is seasonal, its processing, in addition to adding value, allows an increase in the shelflife and consumption of products regardless of the harvest period. In view of this, the present work aims to use of Araticum fruit in the form of a sweet pasty with substitution of commercial pectin for passion fruit albedo, as well as the evaluation of the microbiological and nutritional quality, optimization and sensory of the formulations, focusing on insertion of the fruit in the consumer market. For processing, a $2^{3}$ experimental design was used with 11 tests and 3 independent variables (citric acid, pulp / sugar and passion fruit albedo). Microbiological analyzes, sensory acceptance tests for optimization of formulations, correlation between sensory attributes were analyzed. The 11 formulations obtained good acceptance from the tasters, and formulations 9,10 and 11 were preferred by the optimization models.

Keywords: Araticum, sensory quality, response surface.

\section{INTRODUÇÃO}

O cerrado é o segundo maior bioma do Brasil, ocupando 23,3\% do território nacional, sendo superado apenas pela Amazônia [1]. Além disso, é considerado o segundo maior bioma integral da América Latina, com mais de 2 milhões de quilômetros quadrados, o que equivale à área combinada da Inglaterra, França, Alemanha, Itália e Espanha [2]. É reconhecido como a Savana mais rica do mundo em biodiversidade devido à sua extensão territorial e posicionamento geográfico [3].

A flora do cerrado brasileiro possui grande diversidade de frutos com grande potencial agrícola pouca explorada tecnologicamente. Trabalhos relatam que os frutos do cerrado, in natura ou processados, possuem componentes nutricionais importantes para a saúde humana e sua inclusão na dieta é essencial [4-8].

Nesse sentido, o Araticum é um fruto nativo do cerrado cujo a polpa é rosada ou amarelada, adocicada e rica em compostos bioativos, vitaminas e minerais $[9,10]$. O fruto está entre as 
espécies mais consumidas do bioma, é muito apreciado por sua polpa e sabor característicos que, além do consumo in natura pode ser transformada em doces, geleias, sucos, licores, tortas, iogurtes ou sorvetes [11].

A aplicação de tecnologias pós-colheita, para desenvolvimento de novos produtos a partir de frutos nativos, além de incentivar o consumo de frutos com alto valor nutritivo e funcional, aumentam a vida útil, diversificam as possibilidades de mercado, agregam valor, diminuem o desperdício e ainda, podem se tornar uma opção valiosa de renda ao produtor [12]. Quando se trata de frutos sazonais, como é o caso de grande parte das espécies do cerrado, essa aplicação se torna mais importante ainda, pois permite o consumo de produtos dos frutos durante o ano inteiro.

Nesse sentido, entre as tecnologias utilizadas para agregar valor à frutos, a elaboração de doces é considerada uma das formas mais aceitas pelo consumidor [13]. Esta, é uma alternativa viável e de baixo custo para o uso de frutos do cerrado. Doce em massa é um produto resultante do processamento adequado das partes comestíveis dos vegetais, adicionados de açúcares, água, pectina, ajustador de $\mathrm{pH}$, além de outros ingredientes e aditivos permitidos, até alcançar a consistência adequada, assegurando a estabilidade do produto [14]. A pectina utilizada no preparo de doces constitui o elemento fundamental necessário à formação de gel, e deve ser adicionada quando a fruta não é suficientemente rica nesse componente. A pectina pode ser extraída do albedo da casca de frutas cítricas. O albedo representa cerca de $70 \%$ da casca e é fonte potencial de fibras $[15,16]$. A casca do maracujá, denominada como resíduo apresenta grande quantidade de pectina, visto que o Brasil é atualmente o maior produtor mundial de maracujá amarelo, a utilização desse resíduo é primordial $[17,18]$.

Portanto, o presente trabalho teve como objetivo aproveitar o fruto do Araticum sob a forma de doce em pasta com substituição da pectina comercial por albedo da casca do maracujá, bem como avaliar a qualidade microbiológica e nutricional, e otimizar sensorialmente o doce, com foco na inserção do fruto no mercado consumidor.

\section{MATERIAL E MÉTODOS}

\subsection{Matéria-Prima}

As polpas integrais do Araticum $\left(16^{\circ} 45^{\prime} 06.6^{\prime \prime} \mathrm{S}, 43^{\circ} 52^{\prime} 05.7^{\prime \prime} \mathrm{W}\right)$ foram disponibilizadas pela cooperativa Grande Sertão, (Montes Claros, MG) para o Laboratório de Cinética e Modelagem de Processos na Universidade Federal do Tocantins (UFT, Palmas, TO) através de transporte aéreo, em embalagens térmicas para evitar o descongelamento. As mesmas, foram armazenadas sob congelamento até o processamento.

\subsection{Processamento Dos Doces}

Para o processamento foram seguidas as etapas: recepção das polpas, pesagem dos ingredientes de cada formulação, os ingredientes, exceto ácido cítrico, foram levados a cocção, e próximo do ponto final o ácido foi então adicionado. O processo de cocção foi cessado quando o doce atingiu $78^{\circ}$ Brix. Em seguida, foi realizado o enchimento à quente e fechamento da embalagem. Utilizou-se o albedo de maracujá como fonte de pectina [19].

\subsection{Planejamento Experimental e Otimização}

Para otimização do processamento do doce foi utilizada a metodologia de superfície de resposta com delineamento fatorial completo $2^{3}$ [20] descrito na Tabela 1, que teve por finalidade avaliar a influência de três fatores como a concentração de ácido cítrico, a razão polpa/açúcar e a concentração do albedo como fonte de pectina sobre os atributos aroma, sabor, textura e impressão global. Foi estimado o modelo de otimização incluindo o efeito de interação de acordo com o valor do coeficiente de determinação $\left(\mathrm{R}^{2}\right)$, este assumido como um valor superior a $70 \%$, permitindo inferir que o modelo explica uma elevada porcentagem da variabilidade total. 
Tabela 1: Delineamento experimental $\left(2^{3}\right)$ para os ensaios de elaboração de doce de Araticum. $X 1=$ concentração de ácido cítrico (\%); X2 = razão polpa/açúcar $(\mathrm{m} / \mathrm{m})$ e X3= Concentração de albedo $(\%)$.

\begin{tabular}{ccccccc}
\hline & \multicolumn{3}{c}{ Variáveis codificadas } & \multicolumn{3}{c}{ Variáveis reais } \\
\cline { 2 - 7 } Ensaios & $\mathbf{X 1}$ & $\mathbf{X 2}$ & $\mathbf{X 3}$ & $\mathbf{X 1}(\boldsymbol{\%})$ & $\mathbf{X 2}(\mathbf{m} / \mathbf{m})$ & $\mathbf{X 3}(\boldsymbol{\%})$ \\
\hline $\mathbf{1}$ & +1 & +1 & +1 & 1 & $60 / 40$ & 3 \\
$\mathbf{2}$ & -1 & -1 & +1 & 0 & $40 / 60$ & 3 \\
$\mathbf{3}$ & +1 & -1 & +1 & 1 & $40 / 60$ & 3 \\
$\mathbf{4}$ & -1 & +1 & +1 & 0 & $60 / 40$ & 3 \\
$\mathbf{5}$ & +1 & +1 & -1 & 1 & $60 / 40$ & 0 \\
$\mathbf{6}$ & -1 & +1 & -1 & 0 & $60 / 40$ & 0 \\
$\mathbf{7}$ & +1 & -1 & -1 & 1 & $40 / 60$ & 0 \\
$\mathbf{8}$ & -1 & -1 & -1 & 0 & $40 / 60$ & 0 \\
$\mathbf{9}$ & 0 & 0 & 0 & 0,5 & $50 / 50$ & 1,5 \\
$\mathbf{1 0}$ & 0 & 0 & 0 & 0,5 & $50 / 50$ & 1,5 \\
$\mathbf{1 1}$ & 0 & 0 & 0 & 0,5 & $50 / 50$ & 1,5 \\
\hline
\end{tabular}

\subsection{Análises Microbiológicas}

Para a realização das análises microbiológicas, pesou-se para cada formulação assepticamente uma amostra de $25 \mathrm{~g}$ do doce, esta foi diluída e homogeneizada em $225 \mathrm{~mL}$ de água peptonada $0,1 \%$. As preparações das diluições decimais subsequentes foram realizadas em tubos contendo $9 \mathrm{~mL}$ de água peptonada $0,1 \%$. Todas as análises foram realizadas em triplicata.

Para detecção de Salmonella, esta amostra (diluição $10^{-1}$ ) foi incubada em estufa bacteriológica por $24 \mathrm{~h}$ a $35-17^{\circ} \mathrm{C}$, esta é a etapa de pré-enriquecimento. Após este período, foi realizada a etapa de enriquecimento seletivo, incubando $1 \mathrm{~mL}$ da amostra do dia anterior em caldo seletivo, utilizando $9 \mathrm{~mL}$ do caldo Rappaport, incubados a $35-37^{\circ} \mathrm{C}$ por $24 \mathrm{~h}$. No dia seguinte foi realizado o plaqueamento diferencial, onde foram inoculados $0,1 \mathrm{~mL}$ da amostra do caldo seletivo em superfície de ágar Salmonella Shigella (SS) e ágar Xilose Lisina Desoxiciolato (XLD). Incubadas em $35-37^{\circ} \mathrm{C}$ por $24 \mathrm{~h}$.

As análises de coliformes totais e termotolerantes foram realizadas por meio da contagem do número mais provável (NMP) [21]. Cada diluição foi semeada em 9 tubos contendo caldo Lauril Sulfato Triptose (LST), para a quantificação do número mais provável de coliformes (NMP). Em seguida incubados em estufa bacteriológica a $35-37^{\circ} \mathrm{C}$ por $48 \mathrm{~h}$.

Para quantificação de bolores e leveduras, inoculou-se $0,1 \mathrm{~mL}$ de cada diluição, em superfície de placas previamente preparadas com meio ágar batata dextrose (BDA), usando uma alça de Drigalsky, o inóculo foi espalhado por toda a superfície do meio, até que todo o excesso de líquido fosse absorvido. As placas foram incubadas em B.O.D. a $25^{\circ} \mathrm{C}$ por sete dias. Para a análise de estafilococos coagulase positiva foi utilizada a metodologia de Silva et al. (2001) [22]. As diluições foram inoculadas e superfície em meio sal manitol e posteriormente incubadas a $37^{\circ} \mathrm{C}$ por $48 \mathrm{~h}$.

\subsection{Análise Sensorial}

Para a procedência da análise sensorial, a pesquisa foi submetida previamente ao Comitê de Ética em Pesquisa da Universidade Federal do Tocantins, o qual foi aprovado com o Certificado de Apresentação para Apreciação Ética número 93357718.3.0000.5519 e parecer número 3.096.189. O recrutamento de avaliadores foi realizado por convite oral, por meio de cartazes, redes sociais e outras mídias eletrônicas. Foram admitidos voluntários não treinados de ambos os sexos, com idade entre 18 e 65 anos, com boa saúde (auto referida), que declarassem consumir doces e pudessem retornar no dia anterior para completar avaliação de todas as formulações.

O teste foi realizado no laboratório de análise sensorial (UFT, Palmas, TO), onde as amostras foram servidas em cabines individuais em dois dias consecutivos ( 5 amostras no primeiro e 6 amostras no segundo). As amostras foram preparadas igualmente, com cerca de $10 \mathrm{~g}$ cada, em copos de $50 \mathrm{~mL}$ de cor branca, com identificação numérica de três dígitos aleatórios entre 1 e 9 , para cada amostra [23, 24]. Foram apresentadas em luz branca, temperatura ambiente, em 
bandejas lisas de cor branca, juntamente com biscoito "água e sal", água mineral e a ficha sensorial. Os provadores foram instruídos a fazer uma pausa entre uma análise e outra, servindose desses recursos para minimizar o sabor residual deixado pela prova anterior [25].

Os testes foram realizados em dois dias seguidos, com os mesmos provadores, onde no primeiro dia foram apresentadas 5 amostras e no segundo dia 6 amostras. As amostras foram submetidas a testes afetivos de aceitação para os atributos de aroma, sabor, textura, impressão global e intenção de compra. A escala hedônica estruturada de nove pontos foi utilizada de acordo com as seguintes classificações hedônicas: 1= "Desgostei extremamente" e 9= "Gostei Extremamente" popular para os atributos de aroma, sabor, textura e impressão global. Para atitude de consumo do provador uma escala de 9 pontos estruturada em 1= "Comeria só se fosse forçado(a)" e 9= "Comeria isso sempre que tivesse oportunidade". Para intenção de compra uma escala de cinco pontos estruturados foi utilizada, ancorado pelas hedônicas avaliações: 1= "Certamente não compraria" e $5=$ "Certamente compraria".

Após as avaliações, os resultados obtidos para cada atributo sensorial foram tabulados e analisados por meio do cálculo das médias hedônicas para cada atributo.

\subsection{Análises Estatísticas}

Quanto a avaliação estatística, para otimização das 11 formulações submetidas à análise sensorial, fora utilizada as metodologias de desejabilidade global [26] e superfície de resposta [20] utilizando o programa Statistica 13.1, o mesmo foi usado para elaborar a matriz de correlações sensoriais.

\section{RESULTADOS E DISCUSSÃO}

\subsection{Análises Microbiológicas}

A legislação brasileira RDC n'12/2001 e n'331/2019, e IN No 60 da Agência Nacional de Vigilância Sanitária $[27,28]$ estabelecem que em doces em pasta ou massa e similares, incluindo geleias e doces em calda, a presença de até $10^{4} \mathrm{UFC} / \mathrm{g}$ de bolores e leveduras é permitida. Não houve crescimento de bolores e leveduras para nenhuma formulação, constatando que as amostras estão de acordo com o padrão microbiológico estabelecido pela legislação. Não houve detecção de coliformes totais e termotolerantes nas formulações dos doces através da metodologia dos tubos múltiplos.

A legislação brasileira mais recente (RDC $\left.n^{\circ} 331 / 2019\right)$ estabelece limites para microrganismos do gênero Enterobacteriaceae, que correspondem aos coliformes totais. De acordo com a referida, o limite máximo de presença de Enterobacteriaceae é de $10^{2} \mathrm{NMP} / \mathrm{g}$ [27]. Quanto à Salmonella sp. os resultados mostraram que não houve contaminação das formulações elaboradas, havendo ausência em 25 gramas do alimento, conforme preconizado pela RDC $\mathrm{n}^{\circ}$ $331 / 2019$ [27]. Os resultados para estafilococos coagulase positiva apresentaram-se menores que $10 \mathrm{UFC/g}$, o que comprova as boas práticas de manipulação e processamento dos doces.

\subsection{Análise Sensorial}

Dentre os 34 participantes que avaliaram as 11 formulações durante os dois dias, $64,7 \%$ foram mulheres e $35,3 \%$ homens. A faixa etária predominante foi de 16 a 25 anos $(64,7 \%)$ seguida de $20,6 \%$ de 25 a 35 anos. Em relação à frequência de consumo de doces, observou-se que aproximadamente $45 \%$ dos provadores consomem semanalmente (diariamente, 1 vez por semana e 2 a 3 vezes por semana), indicando o hábito do consumidor pelo produto proposto. Aproximadamente $71 \%$ dos provadores afirmaram gostar muito de doces e, os outros $29 \%$, gostar moderadamente e, $8,9 \%$ dos provadores responderam que já conheciam o fruto Araticum.

A falta de conhecimento acerca do Araticum e, consequentemente, o não consumo do fruto se dá devido à escassez de informações sobre os frutos do Cerrado e, portanto, a sua não inserção no mercado nacional e internacional, muitas vezes associada à sazonalidade [29]. A Figura 1 traz o diagrama de desejabilidade das médias atribuídas pelos provadores para cada atributo sensorial. 


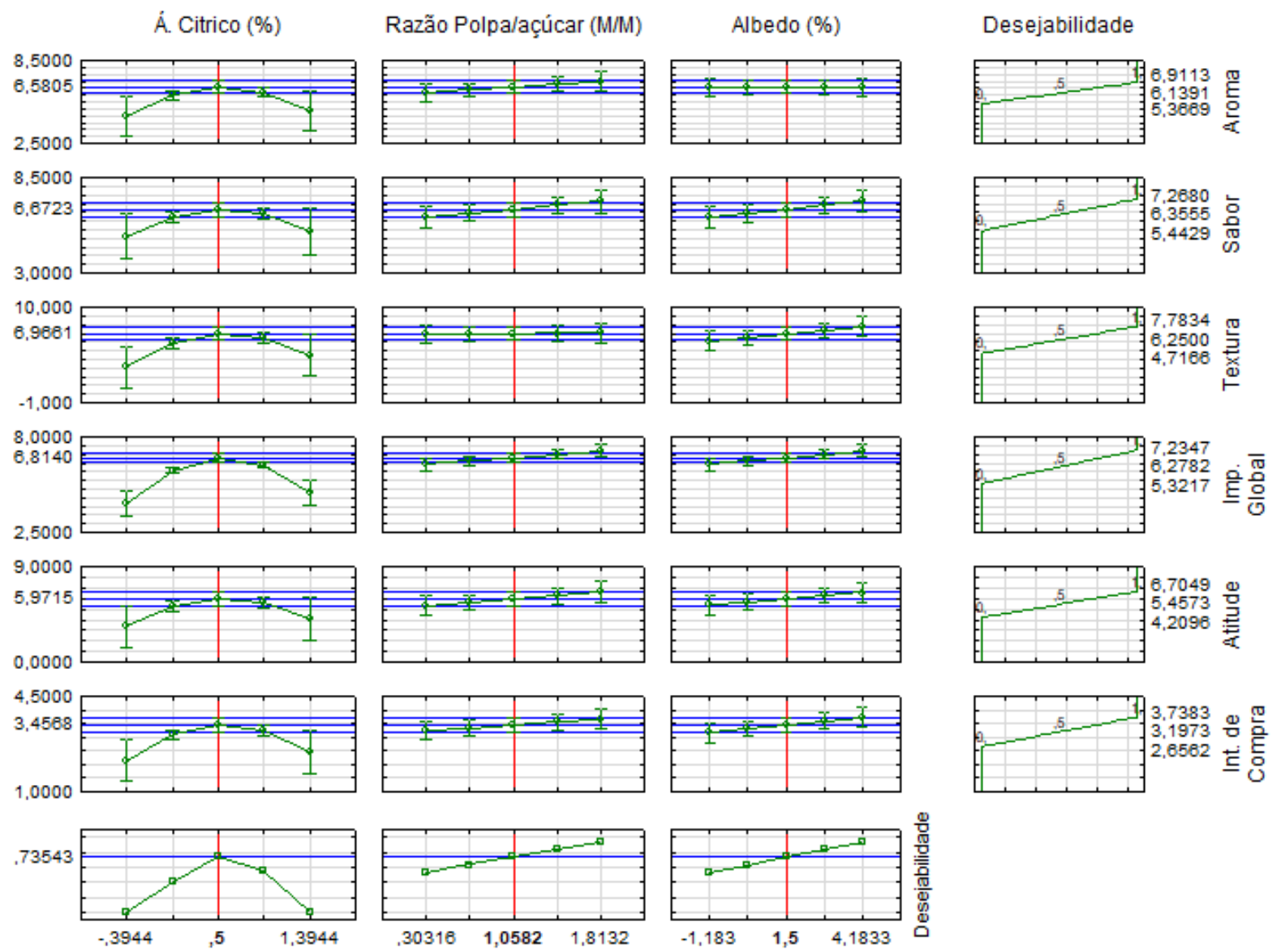

Figura 1: Desejabilidade das formulações dos doces de Araticum em relação aos atributos aroma, sabor, textura, impressão global, atitude de consumo e intenção de compra.

Para os atributos de aroma, sabor e impressão global foi possível observar que as notas ficaram entre 5 e 7 indicando na escala hedônica "nem gostei nem desgostei", "gostei ligeiramente" e "gostei moderadamente", respectivamente. $\mathrm{O}$ atributo textura se aproximou da nota 8 , que na escala hedônica indica "gostei muito". Para o atributo atitude de consumo as notas ficaram entre 4 e 6 , na escala hedônica 4 indica "comeria ocasionalmente" e nota 6 "comeria de vez em quando". Quanto à intenção de compra, as notas ficaram entre 2 (provavelmente não compraria) e 3 (provavelmente compraria). Os resultados de atitude de consumo não foram tão satisfatórios, pelo fato de grande parte dos provadores não conhecerem e não consumirem o fruto, como foi demonstrado nos resultados do questionário apresentado anteriormente.

Como observado (Figura 1), os três últimos perfis mostram a desejabilidade individual para cada fator e a desejabilidade global igual a 0,73543. E ainda, foi possível identificar, através das médias dos atributos sensoriais, como formulação mais desejável aquela que apresentou 50 partes de polpa e 50 partes de açúcar, $1,5 \%$ de albedo e $0,5 \%$ de ácido cítrico. De acordo com o planejamento experimental, estas são as formulações 9, 10 e 11.

\subsubsection{Otimização por Superfície de Resposta}

Após detectadas as melhores formulações pela desejabilidade, ao plotar os gráficos de superfície de resposta para os mesmos dados, foi possível detectar diferentes interações entre os atributos sensoriais em relação às formulações. O atributo aroma (Figuras 2A, 2B e 2C) obteve melhores notas para maiores proporções de polpa e menores proporções de açúcar, observadas nas formulações 1, 4, 5 e 6 com $60 \%$ de polpa e $40 \%$ de açúcar e nas 9,10 e 11 com 50\% de polpa e $50 \%$ de açúcar. Isso indica que os provadores preferiram doces com aroma característico do fruto. 
As melhores notas de polpa/açúcar estão relacionadas com concentrações de ácido cítrico entre 0,4 e $0,8 \%$, as formulações que apresentam $0,5 \%$ de ácido cítrico foram as 9,10 e 11; próximas ao $0,8 \%$ estão as formulações $1,3,5$ e 7 , com $1 \%$ ácido cítrico. Tal resultado está relacionado com o fato de o ácido cítrico conferir e realçar o aroma frutal, característico em doces [30,31]. A partir dos gráficos para o atributo sabor (Figuras 2D, 2E e 2F) foi possível observar que o atributo foi realçado com maiores proporções de polpa, maior concentração de albedo e maiores concentrações de ácido cítrico. Observadas nas formulações 1, com $60 \%$ de polpa e $40 \%$ de açúcar, $3 \%$ de albedo e $1 \%$ de ácido cítrico, observado também nas formulações 9,10 e 11 com $50 \%$ de polpa e $50 \%$ de açúcar, $1,5 \%$ de albedo e $0,5 \%$ de ácido cítrico. Os resultados indicam que as formulações com concentração maior de polpa obtiveram maior preferência, o que demonstra o interesse do provador no sabor característico do fruto. Já o ácido cítrico e o albedo exercem uma função de reter e realçar o sabor natural do fruto [31, 32].
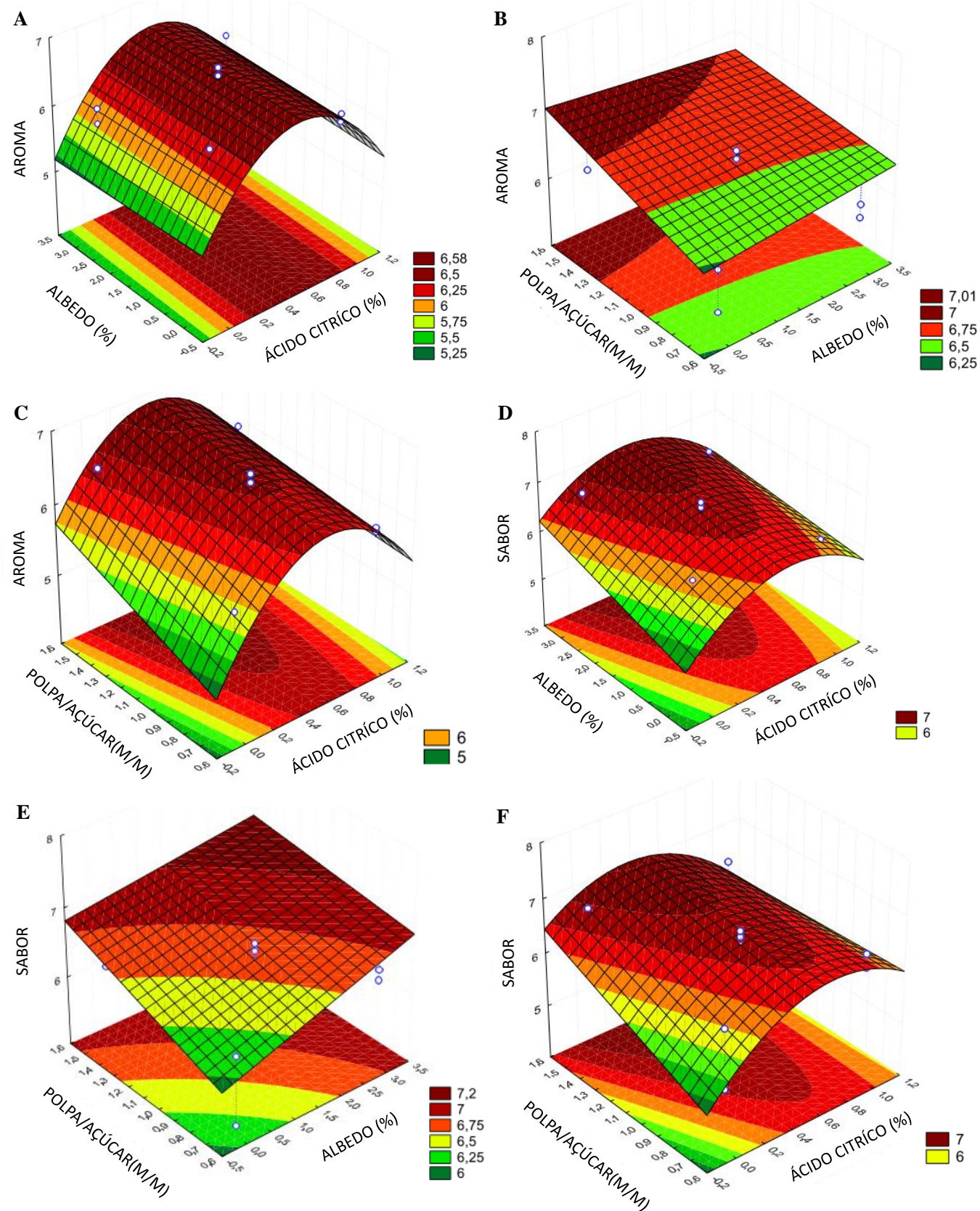

Figura 2. Gráficos dos atributos e suas interações. Aroma em função do Ácido cítrico x Albedo (A), Polpa\Açúcar x Albedo (B) e Ácido cítrico x Polpa\Açúcar (C); Sabor (D, E e F). 
Para o atributo de textura (Figuras 3A, 3B e 3C) foi possível observar que a interação da proporção de polpalaçúcar com ácido cítrico apresentou região ótima em todas as concentrações. Portanto, as formulações 1 e 3 apresentaram melhores texturas com a concentração máxima utilizada, de ácido cítrico (1\%), visto que a proporção polpa/açúcar não influenciou os resultados. Tal resultado se dá pelo fato de que o ácido cítrico auxilia no desenvolvimento de uma textura adequada ao doce devido à sua influência no $\mathrm{pH}$, que contribui para processo de formação do gel durante o processamento. Quando o $\mathrm{pH}$ se encontra baixo demais $(<3,1)$ ocorre rompimento do gel e saída de água, já pH muito alto $(>3,6)$, não permite a formação do gel [33, 34].

Para o atributo impressão global (Figuras 3D, 3E e 3F) foi possível observar a atratividade do provador por formulações com maiores proporções de polpa/açúcar e de ácido cítrico em uma mesma formulação. Este resultado reflete os demais atributos sensoriais avaliados, que demonstraram o mesmo comportamento, comprovando que no geral os doces com mais aroma e sabor do fruto Araticum foram mais preferidos, recebendo as melhores notas. Os resultados observados correspondem as formulações 9,10 e 11 .
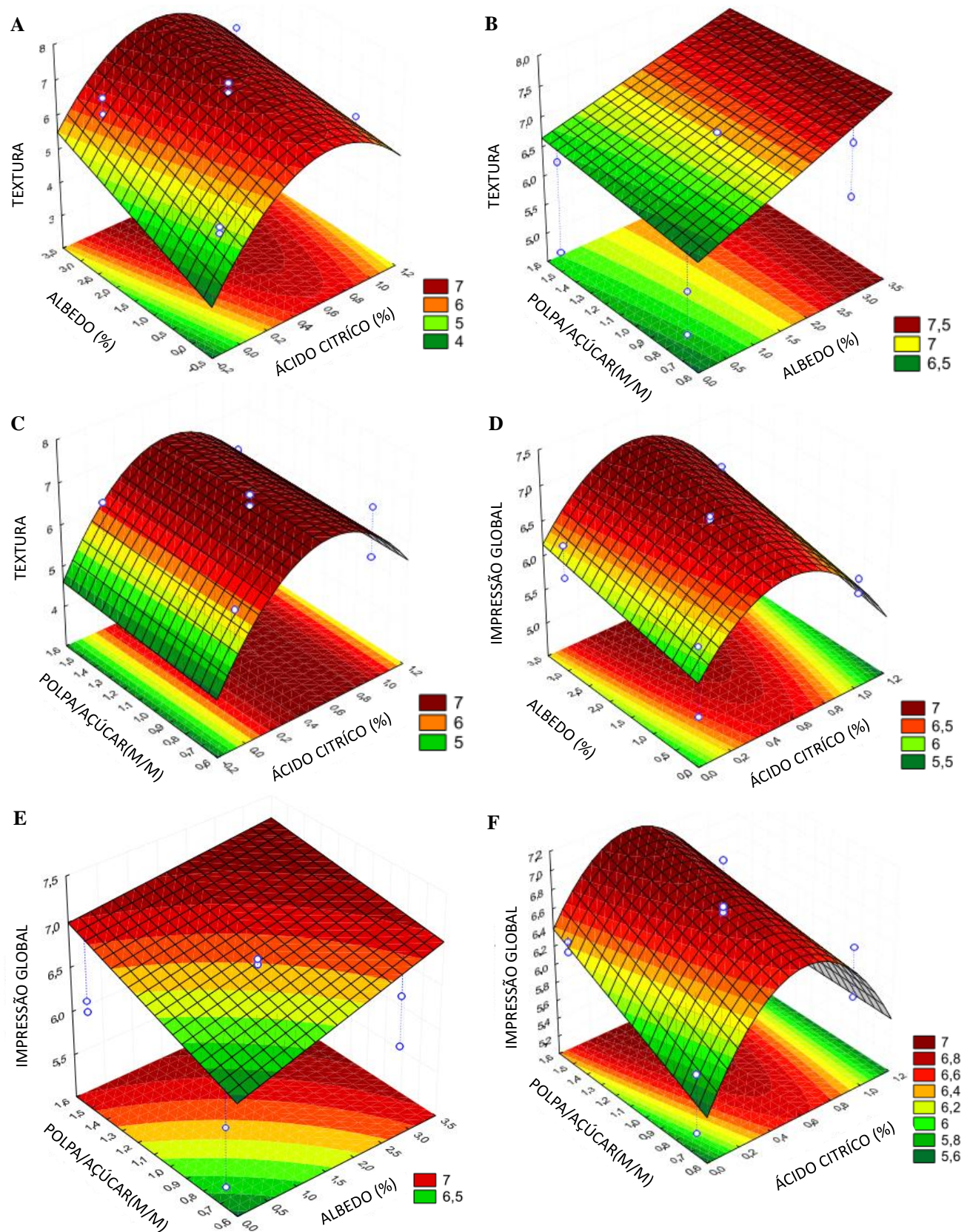

Figura 3. Gráficos dos atributos e suas interações. Textura em função do Ácido cítrico x Albedo (A), Polpa\Açúcar $x$ Albedo (B) e Ácido cítrico x Polpa\Açúcar (C); Impressão Global (D, E e F). 


\subsubsection{Correlação de atributos sensoriais}

Quanto à correlação entre os atributos (Tabela 2), verificou-se correlação significativa $(\mathrm{p}<0,01)$, sendo que a maior delas ocorreu entre a "Impressão global" e "Atitude de consumo" ( $\mathrm{r}$ $=0,96)$, seguida da correlação entre a "Impressão global" e "Intenção de compra" $(r=0,94)$. A impressão global do doce interferiu na atitude de consumo e na intenção de compra, ou seja, a aparência geral do doce influenciará a opinião do consumidor quanto ao produto no mercado, fazendo com que o consumidor o compre e o consuma.

Este resultado corrobora com o observado no gráfico de superfície de resposta mostrado anteriormente, onde, a impressão global apresentou interferência da polpa e ácido cítrico em maiores concentrações, devido ao fato de esses ingredientes realçarem os atributos de aroma e sabor característicos do fruto. A textura foi o atributo que obteve uma correlação mais fraca com demais atributos avaliados, demonstrando que houve pouca influência desse atributo na escolha do consumidor. Corroborando com os resultados apresentados na superfície de resposta, que demonstrou que os ingredientes não interferiram nesse atributo, e ainda que o mesmo não influenciou na impressão global dos doces. E ainda, o atributo "Sabor" foi o que mais influenciou na impressão global, atitude de consumo e intenção de compra do provador.

Tabela 2: Matriz de correlação entre os atributos avaliados. Significativo a 5\% de probabilidade.

\begin{tabular}{lcccccc}
\hline \multicolumn{1}{c}{ Atributo } & Aroma & Sabor & Textura & $\begin{array}{c}\text { Impressão } \\
\text { global }\end{array}$ & $\begin{array}{c}\text { Atitude de } \\
\text { consumo }\end{array}$ & $\begin{array}{c}\text { Intenção } \\
\text { de compra }\end{array}$ \\
\hline Aroma & 1 & 0,77 & 0,46 & 0,88 & 0,83 & 0,71 \\
Sabor & 0,77 & 1 & 0,60 & 0,89 & 0,94 & 0,84 \\
Textura & 0,46 & 0,60 & 1 & 0,77 & 0,70 & 0,84 \\
Impressão global & 0,88 & 0,89 & 0,77 & 1 & 0,96 & 0,94 \\
Atitude de consumo & 0,83 & 0,94 & 0,70 & 0,96 & 1 & 0,93 \\
Intenção de compra & 0,71 & 0,84 & 0,84 & 0,94 & 0,93 & 1 \\
\hline
\end{tabular}

\section{CONCLUSÃO}

As 11 formulações obtiveram boa aceitação dos provadores. No entanto, as formulações otimizadas a partir da interação com os atributos sensoriais e ingredientes foram as 9,10 e 11, apresentando 50 partes de açúcar, 50 partes de polpa, 1,5\% de ácido cítrico e 3\% de albedo de maracujá. A partir dos dados de superfície de resposta foi observado que os provadores demonstraram maior preferência por doces com maior concentração de polpa do fruto e ácido cítrico nas formulações. E ainda, os atributos sensoriais Aroma e Sabor foram os que mais influenciaram na Impressão Global dos doces. A correlação entre os atributos avaliados permitiu observar que os provadores julgaram que a impressão global influencia a atitude de consumo e intenção de compra do doce, e o atributo que menos influenciou na impressão global foi a textura, sendo essa a variável que menos sofreu influência das variáveis estudadas.

\section{REFERÊNCIAS BIBLIOGRÁFICAS}

1. Instituto Brasileiro de Geografia e Estatística (IBGE), Coordenação de Recursos Naturais e Estudos Ambientais. Biomas e sistema costeiro-marinho do Brasil. Rio de Janeiro: IBGE; 2019. (Relatórios metodológicos; vol. 45).

2. Lahsen M, Bustamante MMC, Dalla-Nora EL. Undervaluing and overexploiting the Brazilian Cerrado at Our Peril. Environ Sci Policy Sustain Dev. 2016 Nov 9;58(6):4-15. doi: 10.1080/00139157.2016.1229537

3. Françoso RD, Haidar RF, Machado RB. Tree species of South America central savanna: endemism, marginal areas and the relationship with other biomes. Acta Bot Brasilica. 2016 Mar;30(1):78-86. doi: 10.1590/0102-33062015abb0244

4. Arruda HS, Pereira GA, Pastore GM. Brazilian Cerrado fruit Araticum (Annona crassiflora Mart.) as a potential source of natural antioxidant compounds. Int Food Res J. 2018; 25(5):2005-12. 
5. Schiassi MCEV, de Souza VR, Lago AMT, Campos LG, Queiroz F. Fruits from the Brazilian Cerrado region: Physico-chemical characterization, bioactive compounds, antioxidant activities, and sensory evaluation. Food Chem. 2018 Apr;245:305-11. doi: 10.1016/j.foodchem.2017.10.104

6. de Almeida AB, Silva AKC, Lodete AR, Egea MB, Lima MCPM, Silva FG. Assessment of chemical and bioactive properties of native fruits from the Brazilian Cerrado. Nutr Food Sci. 2019 May 13;49(3):381-92. doi: 10.1108/NFS-07-2018-0199

7. Oliveira VF, Silva FG, Resende EC, Pereira PS, e Silva FHL, Egea MB. Physicochemical characterization of 'Cerrado' cashew (Anacardium othonianum Rizzini) fruits and pseudofruits. J Sci Food Agic. 2019 Nov 9;99(14):6199-208. doi:10.1002/jsfa.9892

8. Batista FO, Sousa RS. Bioactive compounds in fruits pequi (Caryocar brasiliense Camb.) e baru (Dipteryx alata Vogel) and their potential uses: a review. Braz J Develop. 2019;5(7):9259-70. doi: $10.34117 / \mathrm{bjdv} 5 \mathrm{n} 7-120$

9. Aguiar AO, Rodrigues DDS, Sousa AR, Soares CMS, Ibiapina A, Melo Filho AA, et al. Use of passion fruit albedo as a source of pectin to produce Araticum (Annona crassiflora Mart.) preserves. Chem Engineering Transactions, 2019;75(2019):223-228. doi: 10.3303/CET1975038

10. Aguiar AO, Souza ARM, Oliveira MOS. Araticum (Annona Crassiflora Mart.). In: de Souza ARM, Daminani C, Martins GAS, da Silva JFM, organizadores. Frutos do Cerrado: características e aplicações tecnológicas. Curitiba (PR): CRV; 2018. p. 85-96.

11. Arruda HS, Fernandes RVB, Botrel DA, Almeida MEF. Frutos do Cerrado: Conhecimento e aceitação de Annona crassiflora Mart. (Araticum) e Eugenia dysenterica Mart. (Cagaita) por crianças utilizando o paladar e a visão. J Heal Biol Sci. 2015 Dec 17;3(4):224-30. doi: 10.12662/23173076jhbs.v3i4.168.p224-230.2015

12. Arruda HS, Botrel DA, Fernandes RVB, Ferreira de Almeida ME. Development and sensory evaluation of products containing the Brazilian Savannah fruits araticum (Annona crassiflora Mart.) and cagaita (Eugenia dysenterica Mart.). Braz J Food Technol. 2016;19:e2015105. doi: 10.1590/1981-6723.10515

13. Freitas MLF, Menezes CC, Carneiro JDS, Reis RP. Diagnóstico do consumo e processo produtivo de doces de frutas produzidos artesanalmente. Alim Nutr. 2012;23(4):589-95.

14. Associação Brasileira das Indústrias de Alimentação (ABIA). Compêndio de legislação dos alimentos: Consolidação das normas e padrões para alimentos. São Paulo: Abia; 2001.

15. Zain NFM, Yusop SM, Ahmad I. Preparation and characterization of cellulose and nanocellulose from pomelo (Citrus grandis) albedo. J Nutr Food Sci. 2015;5(1):1000334. doi:10.4172/2155-9600.1000334

16. Cheong M-W, Loke X-Q, Liu S-Q, Pramudya K, Curran P, Yu B. Characterization of volatile compounds and aroma profiles of malaysian pomelo (Citrus grandis (L.) Osbeck) blossom and peel. J Essent Oil Res. 2011 Mar 8;23(2):34-44. doi: 10.1080/10412905.2011.9700445

17. Instituto Brasileiro de Geografia e Estatística (IBGE) [Internet]. Produção Agrícola - Lavoura permanente. Maracujá; 2019 [citado em 2021]. Disponível em: https://cidades.ibge.gov.br/brasil/pesq uisa/ $15 / 0$

18. Food and Agriculture Organization of the United Nations (FAO). Food outlook: Biannual report on global food markets. Rome (IT): FAO: 2018. Disponível em: https://reliefweb.int/report/world/foodoutlook-biannual-report-global-food-markets-july-2018

19. Silva IG, Martins GAS, Borges SV, Marques GR, Regis IS. Influence of passion fruit albedo, citric acid, and the pulp/sugar ratio on the quality of banana preserves. Food Sci Technol. 2012 Apr 12;32(2):26773. doi:10.159/S0101-20612012005000038

20. Box GEP, Draper NR. Response surfaces, mixtures, and ridge analyses. 2nd ed. New York (US): John Wiley \& Sons; 2007.

21. Feng P, Weagant SD, Grant MA. Enumeration of Escherichia coli and the Coliform Bacteria. In: AOAC, editor. Bacteriological Analytical Manual (BAM) [Internet]. United States of America: FDA; 1998 [revisado em out 2020; citado em 2021]. Disponível em: https://www.fda.gov/food/laboratorymethods-food/bacteriological-analytical-manual-bam

22. Silva N, Junqueira VCA, Silveira NFA. Manual de métodos de análise microbiológica de alimentos. São Paulo: Varela; 2001.

23. Stone H, Bleibaum RN, Thomas HA. Sensory evaluation practices. 4. ed. San Diego (CA): Academic Press (Elsevier); 2012.

24. MacFie HJ, Bratchell N, Greenhoff K, Vallis LV. Designs to balance the effect of order of presentation and first-order carry-over effects in hall tests. Journal of Sensory Studies. 1989;4(2):129-48.

25. Esmerino EA, Castura JC, Ferraz JP, Tavares Filho ER, Silva R, Cruz AG, et al. Dynamic profiling of different ready-to-drink fermented dairy products: A comparative study using Temporal Check-AllThat-Apply (TCATA), Temporal Dominance of Sensations (TDS) and Progressive Profile (PP). Food Res Int. 2017 Nov;101:249-58. doi: 10.1016/j.foodres.2017.09.012

26. Harrington Junior EC. The desirability function. Industrial Quality Control. 1965. 21(10):494-8. 
27. Brasil. Ministério da Saúde, Agência Nacional de Vigilância Sanitária (ANVISA). RDC no 331, de 23 de dezembro de 2019. Dispõe sobre os padrões microbiológicos de alimentos e sua aplicação. Diário Oficial da União. 26 dez 2019;249(Seção 1):96. Disponível em: https://www.in.gov.br/en/web/dou//resolucao-rdc-n-331-de-23-de-dezembro-de-2019-235332272

28. Brasil. Ministério da Saúde, Agência Nacional de Vigilância Sanitária (ANVISA). Resolução RDC no 12, de 02 de janeiro de 2001. Aprova o Regulamento Técnico sobre padrões microbiológicos para alimentos. Diário Oficial [da] República Federativa do Brasil. 10 jan 2001;7-E(Seção 1):45-53. Disponível em: https://bvsms.saude.gov.br/bvs/saudelegis/anvisa/2001/res0012_02_01_2001.html

29. Morzelle MC, Bachiega P, de Souza EC, Vilas Boas EVDB, Lamounier ML. Caracterização química e física de frutos de curriola, gabiroba e murici provenientes do cerrado brasileiro. Rev Bras Frutic. 2015 Mar;37(1):96-103. doi: 10.1590/0100-2945-036/14

30. Brasil FI. Aplicações do ácido cítrico na indústria de alimentos. Food Ingredients Brasil, 2014;(30):96103.

31. Cunha MF, Ribeiro LMP, Damasceno KA, Alves AN, Gonçalves RMS, Gonçalves CAA. Acidez, sua relação com pH e qualidade de geleias e doces em barra. Boletim técnico IFTM. 2016;2(2):14-19.

32. Torrezan R. Doce em massa. Brasília (DF): Embrapa; 2015.

33. Soler MP, Fadini AL, Hilst MAS, Okada CE. Frutas: compotas, doce em pasta, geleias e frutas cristalizadas para micro e pequena empresa. Campinas (SP): Instituto de Tecnologia de Alimentos (ITAL); 1995.

34. Lopes RLT. Dossiê técnico: Fabricação de geleias. Belo Horizonte (MG): CETEC; 2007. 